\title{
La crónica visual de un golpe de estado anunciado
}

Christabelle Roca-Rey Ross

King's College, University of London

En 1967, un año antes del golpe de estado del General Juan Velasco Alvarado que depone del poder al presidente Fernando Belaunde Terry, una serie de caricaturas aparecen publicadas en varios medios de prensa. A pesar de las distintas tendencias políticas de estos periódicos y revistas, en todos ellos, el presidente de la República aparece representado como un líder débil, desorientado y poco apto a seguir dirigiendo el país. En este artículo, explico cómo estas caricaturas pudieron haber favorecido el golpe militar, creando un desafecto en la población hacia la figura del presidente Belaunde, así como por la democracia.

Caricatura / golpe de estado

In 1967, a year before the coup d'état of General Juan Velasco Alvarado, that overthrew the President Fernando Belaunde Terry, a series of cartoons were published in different medias. Despite having different political opinions, all these newspapers and magazines depicted the president as a weak and disoriented leader that seemed unable to run the country. In this article, I explain how these cartoons had a decisive impact on the coup d'état, creating a general dislike towards the President Belaunde and democracy.

Cartoon / coup d'état

En setiembre de 1967, el Banco Central de Reserva del Perú se queda sin divisas y el Gobierno se ve obligado a devaluar la moneda en medio de un gigantesco déficit público. Las caricaturas publicadas después de esta devaluación permiten apreciar no solo la posición asumida por cada uno de los medios de prensa, sino también la manera en que las caricaturas fueron una herramienta particular para introducir ciertos discursos políticos en la esfera pública. La inclusión de una sección de humor gráfico en los periódicos ha sido una constante en la historia del periodismo peruano: "El humor y la caricatura -quizá su variedad más apreciada-", escribe Juan Gargurevich, "están presentes prácticamente en todos nuestros periódicos. La sátira fina, la burla cruel han sido con frecuencia las armas favoritas para combatir en las casi constantes tempestades políticas de la historia del país ${ }^{\prime \prime}$. En esos años, todos los medios de prensa importantes del país contaban con un espacio dedicado a publicar caricaturas y, en la mayoría de casos, con un dibujante designado específicamente para transmitir de manera visual las opiniones del periódico o revista. Si bien no es posible dar un juicio preciso acerca del impacto que tuvieron estas caricaturas en la población lectora de medios masivos, en este artículo veremos cómo la publicación continua de imágenes en los medios de prensa en donde el presidente Fernando Belaunde Terry aparece representado como un líder ineficaz y poco popular, pudo haber favorecido el golpe de Estado del General Juan Velasco Alvarado.

1 Gargurevich, 1991: 136. 
En una caricatura publicada por el diario El Comercio y hecha por el dibujante Guillermo Osorio (Arequipa, 1935-1972), a principios de setiembre de 1967 (Fig. 1), este discurso crítico hacia Belaunde Terry se refleja a través de la representación del presidente como un doctor que no posee la medicina que logrará curar a su paciente, el "Sol". Si Osorio opta aquí por la analogía médica es porque las metáforas sobre política económica y salud eran empleadas desde hace décadas por los economistas. Es el caso, por ejemplo, del economista John Maynard Keynes, quien en su libro de 1930 Treatise on Money. The Applied Theory of Money compara la crisis económica con un niño enfermo al que hay que suministrarle un remedio $^{2}$. Este mismo tipo de analogía la realiza el economista Irvin Fisher, en su artículo de 1933 "Debt-deflation theory of great depressions", donde compara el sobreendeudamiento y la deflación con un resfriado que termina en neumonía ${ }^{3}$. Esta analogía visual empleada por Osorio entre política económica y medicina se inspira entonces del modo verbal, y confirma la teoría del historiador de arte Ernst Gombrich según la cual una de las principales características del humor gráfico se basa en la libertad de transferir los conceptos y los símbolos cursivos del lenguaje en representaciones visuales ${ }^{4}$.

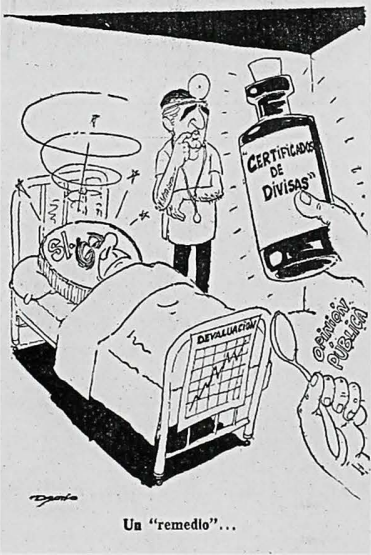

Fig.1 Guillermo Osorio, El Comercio, 6 setiembre 1967, p.2.

La utilización del universo médico es una analogía con la cual el lector puede sentirse fácilmente familiarizado, reconociendo inmediatamente las tensiones inherentes entre paciente, doctor, enfermedad y remedio. En la imagen citada, la condición dramática del "Sol" que se refleja a través de sus cejas y labios caídos, de los círculos oscuros alrededor de sus ojos, de las estrellas, las líneas discontinuas y circulares, sugiere la expectativa por un desenlace: la recuperación o la muerte; es decir, la salida de la crisis económica o el hundimiento de la moneda y por lo tanto del país. Además del binomio médico/ paciente que aparece en esta caricatura, por el lado derecho de la imagen surge un tercer personaje representado únicamente por dos manos y que adopta una actitud médica para suplir la ineficiencia de Belaunde: la mano izquierda sostiene una cuchara, mientras la mano derecha sostiene un frasco en forma de jarabe que dice "certificados de divisas". Se trata, como lo indica la leyenda en medio de ambas manos, de la "opinión pública", que ofrece el remedio para curar al "Sol". El diario no solo ilustra una situación dramática, sino que se erige como un portavoz de la voluntad popular. En esta caricatura, la "opinión pública" se presenta en una actitud activa haciendo un reclamo, mientras que el poder ejecutivo, representado por la figura de Belaunde es, en contraposición, una fuerza que no logra controlar la situación económica del país. Si bien no puede considerarse que El

2 Keynes, 1930: 223.

3 Fisher, 1933: 337-357.

4 Gombrich, 2003:139. 
Comercio presenta al presidente como un "villano" de tira cómica puesto que su expresión dubitativa, representada a través de sus cejas caídas, su brazo cruzado y su dedo sobre el labio indican más que todo ineptitud y no malicia; sí se puede observar que a pesar de haber defendido anteriormente al Gobierno belaundista, el diario de los Miró Quesada transmite a partir de setiembre de 1967 un discurso crítico sobre el presidente Belaunde.

Para Gombrich ${ }^{5}$, el caricaturista es capaz de transformar el mundo político en un universo mítico a través de las metáforas visuales: "El humorista al dar una fisionomía al mundo político, puede transformarlo en un universo mítico. Asociando a lo real, un elemento mítico, él crea esa fusión, esa amalgama que puede parecer tan convincente para un espíritu emotivo $^{6 "}$. Estas metáforas serían entonces un recurso clave del caricaturista porque es lo que le permiten crear un universo político "mítico" que viene a entremezclarse con el universo político "real". Gombrich no solo menciona la existencia de dos niveles de lectura en la caricatura -uno real y otro ficticio-, sino también afirma que estos dos universos pueden llegar a confundirse bajo los ojos del lector, logrando que éste observe la política bajo la mirada imaginaria del caricaturista. Basándonos en esta teoría, podemos suponer que así como el "Sol" aparece frente al lector como un ser humano con dolencias, Belaunde puede ser recordado también por el público como un médico que no logra curar a su paciente.

A pesar de no ser argumentada, y requerir por ello de un rápido vistazo para ser captada, la caricatura de $E l$ Comercio es un ataque al prestigio del presidente. "Los comentarios e insultos transmitidos en el simbolismo gráfico de una caricatura", escribe Seymour-Ure ${ }^{7}$, "son tan crudos y ofensivos que sería inaceptable ponerlos en palabras". Al representarlo como un "anti-líder", El Comercio hace que el lector sienta desafecto y menosprecio por el mandatario peruano. "Aun cuando el propósito no fuera dañar físicamente a la víctima", escribe Gombrich", "la intención sigue siendo con todo dañar su persona, su posición en esa red de convenciones culturales [...], de hecho, todo lo que la distingue de un animal y se experimenta como honor". Esta intención de dañar la persona de Belaunde, en palabras de Gombrich, aparece claramente en la caricatura de El Comercio. Presentar al presidente como un médico sin remedios para curar a su paciente enfermo, es ante todo declarar a Belaunde incapaz de plantear una solución y de ponerla en práctica, y por extensión, es declararlo incapaz de cumplir su rol como Jefe de Estado. Esta caricatura muestra el inicio de una campaña que implica el desprestigio constante y consistente de la figura de Belaunde, no solo por el diario El Comercio, sino también por diarios con otras tendencias políticas, como el diario aprista La Tribuna (Fig. 2).

Fundado en 1931 por Manuel Seoane, La Tribuna era probablemente, de todos los diarios, el más crítico hacia el Gobierno de Belaunde. Esto se debía a que, durante las elecciones de 1962, el líder del partido aprista, Víctor Raúl Haya de la Torre no había podido acceder a la presidencia, ya que las Fuerzas Armadas habían favorecido la subida al poder de Fernando Belaunde $^{10}$. El dibujante de La Tribuna, Carlos Roose Silva (Trujillo, 1929), que firmaba en general bajo el seudónimo "Crose", presenta en una caricatura publicada un día después de la anteriormente citada, la escena dramática del hundimiento de un barco en el que Belaunde aparece como el capitán.

5 Ibidem: 139.

6 "Lhumoriste, en donnant au monde politique une physionomie, peut le transformer en univers mythique. En rattachant au réel un élément mythique, il crée cette fusion, cet amalgame qui peut paraître si convaincant pour un esprit émotif" [Cita original].

7 Seymour-Ure, 1986: 176.

8 "The comments and insults conveyed in the graphic imagery of a cartoon have a crudity and offensiveness that might well be unacceptable if spelt out in words" [Cita original].

9 Gombrich, 1999: 193.

10 Prieto Celi, 2010: 131-138. 
DIBUIO DEL DIA

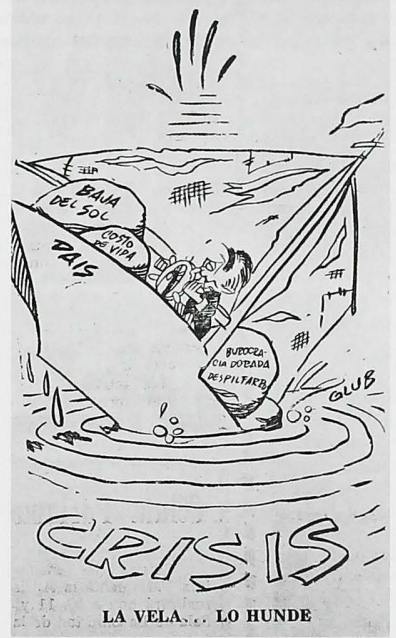

Fig.2. Carlos Roose Silva, La Tribuna, 7 setiembre 1967. p. 2.
Presentar el barco de este modo, es sugerir que el proyecto político de Belaunde ha llevado al país a un proceso de quiebre. La escena, que se inspira del modo verbal (en términos metafóricos, un plan económico deficiente es asociado a un barco naufragando ${ }^{11}$ ) parece confirmar nuevamente que el caricaturista saca partido de todo lo que el lenguaje ha vuelto aceptable. La manifiesta "hostilidad" y "agresividad" hacia Belaunde toma forma a través de diferentes elementos. En primer lugar, a través de sus rasgos físicos exagerados: cejas pobladas que le ocultan los ojos, sienes canosas, nariz imponente y labios pulposos; así como por su traje de frac que lo presenta como un oligarca. La "burocracia dorada", el "despilfarro", la "baja del sol" y el "costo de vida", son producto de decisiones gubernamentales equivocadas. La representación de un barco -metáfora del "país"como uno que ha pasado por un proceso de deterioro, con una vela que tiene agujeros, parches y rasgaduras, también contribuye a enfatizar este discurso crítico sobre el Gobierno belaundista. Tanto las líneas circulares en el agua, como las burbujas sobre el barco, que se asemejan a los dedos de una mano suplicando ayuda, y la onomatopeya "glub" evocan un naufragio inminente, y por lo tanto enfatizan el carácter dramático de la escena, cuyo desenlace parece próximo.

No se puede medir con exactitud el impacto que tuvieron dichas caricaturas en el público de entonces, pero sí se puede considerar que durante este período, el discurso político sobre Belaunde como un presidente frágil tuvo aceptación en diferentes "esferas mediáticas", puesto que no solo El Comercio y La Tribuna son los que transmiten estas ideas sobre el presidente, sino también otros medios periodísticos como La Prensa y La Olla.

En una caricatura publicada el 8 de setiembre de 1967 (Fig. 3), el dibujante de La Prensa, Julio Fairlie (Arequipa, 1922-2012) representa al mandatario peruano como un jardinero que no logra mantener a sus flores con vida. Según Koetzle y Brunell ${ }^{12}$, existen cuatro aspectos de la personalidad de los políticos que más interesan a los caricaturistas: "moralidad", "honestidad", "liderazgo" y "conocimiento". Basándonos en la clasificación de Koetzle y Brunell, se puede afirmar que Fairlie no realiza un discurso crítico en base a la dimensión ética de Belaunde ("moralidad" y "honestidad"), sino más bien en base a su capacidad intelectual ("liderazgo" y "conocimiento").

11 Herrera-Soler y White, 2012: 113

12 Koetzle y Brunell, 1996: 111-113. 
Esta caricatura de Fairlie se presenta a primera vista como una escena sin dramatismos por el contexto campestre en el que se desarrolla y por la representación de Belaunde como un simple jardinero con camisa remangada, overol y regadera en mano. A pesar del entorno apacible, la expresión facial de Belaunde sugiere una escena dramática, puesto que aparece encorvado, con los labios en línea recta y con las cejas caídas. El motivo de su aflicción parece explicarse por la flor marchita que representa la disolución del Gabinete del Ministro Daniel Becerra. Siendo la flor el

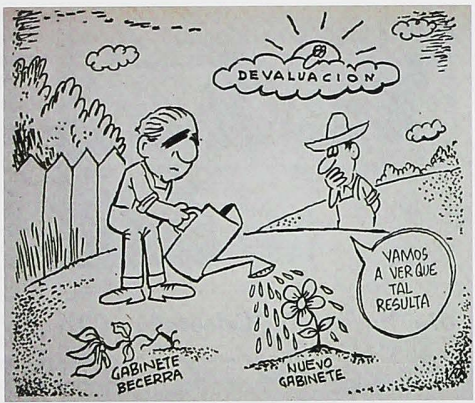

Fig.3. Julio Fairlie, La Prensa, 8 setiembre 1967, p. 13. símbolo de la fragilidad y de lo efímero, el caricaturista parece evocar a través de esta metáfora que los Gobiernos compuestos por Belaunde carecen de fortaleza y no logran perdurar. La devaluación de la moneda -causa del marchitamiento de la "flor Becerra"- aparece representada a través de una analogía, que asocia una nube con la devaluación, y al astro solar con la moneda nacional. Si bien el presidente riega una flor que representa el nuevo gabinete, su actitud cabizbaja ilustra la fragilidad de la situación. Otros elementos también contribuyen a proyectar esta imagen pesimista sobre la situación nacional, como los párpados a medio cerrar del astro solar; o el jardinero anónimo en un segundo plano que observa la escena, y cuya mano en la boca indica preocupación. Este jardinero anónimo en un segundo plano puede ser considerado como una encarnación de la 'opinión pública', ya que su distancia de la escena le permite tener un panorama global de lo que sucede, y sus comentarios -"vamos a ver qué tal resulta"- lo presentan como un personaje que tiene un conocimiento de los hechos.

El caricaturista francés Jean Plantureux ${ }^{13}$, alias "Plantu", afirma que la asociación de dos temas distintos de la actualidad es un recurso que él utiliza frecuentemente: "Relacionar un tema con otro es un recurso que me gusta mucho utilizar. Como en los juegos de palabras, los juegos de signos permiten unir dos imágenes, creando una tercera, inesperada ${ }^{14 "}$. Así como Plantu, varios dibujantes peruanos parecen utilizar este recurso retórico. Es el caso por ejemplo de Hernán Bartra, apodado "Monky" (Iquitos, 1932), quien en una caricatura del semanario La Olla (Fig. 4), asocia el lanzamiento del Surveyor VII hacia la luna, el 7 de enero de 1967, con la situación política del país.

La Olla, creada en 1966 por el periodista Alfonso Baella Tuesta, era una revista de actualidad que semanaimente comentaba una gran parte de los temas políticos, económicos y sociales del momento a través de numerosas caricaturas. Si bien la página editorial era un lugar clave para la caricatura política de esos años, la portada y el espacio de la página entera ofrecían mayores posibilidades expresivas y de impacto. Recoger colaboraciones de los dibujantes más conocidos de la época, entre los que se encuentran Guillermo Osorio,

13 Plantureux, 1998:4

14 "Raccrocher un sujet à un autre c'est un procédé que j’aime bien utiliser. Comme pour les jeux de mots, les jeux de signes permettent de marier deux images pour en créer une troisième, inattendue" [Cita original]. 


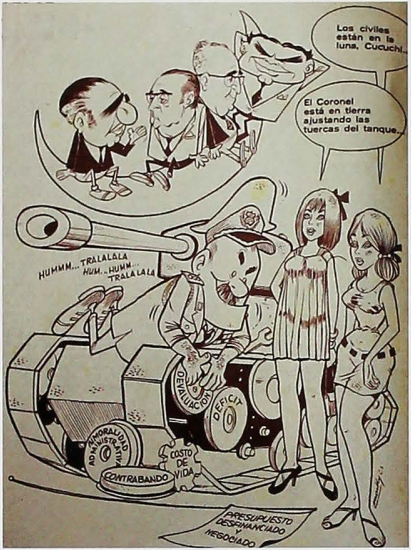

Fig.4 Hernán Bartra, La Olla, 31 de enero de 1968, p.18.

Hernán Bartra, Eduardo Bielich, Luis Baltazar y Víctor Marcos, le da a este semanario algo que otros periódicos y revistas de entonces no poseían: una gran variedad gráfica.

Retomando el contexto de la carrera espacial que existía en los años sesenta entre los Estados Unidos y la Unión Soviética, y representando de manera satírica la expresión verbal "estar en la luna" que significa estar "fuera de la realidad, sin darse cuenta de lo que está ocurriendo ${ }^{15}$ ", esta caricatura mezcla el humor con la actualidad nacional e internacional. Visualmente, vemos que hay una dicotomía entre los políticos "pasivos" en la luna y el coronel de las Fuerzas Armadas que se caracteriza por su dinamismo en la tierra. En el diálogo de los personajes femeninos hay también una diferenciación verbal entre los "civiles" que "están en la luna", es decir desvinculados de la realidad, y el coronel que está en "tierra", lo que implica su contacto con la actualidad. Monky presenta así a Belaunde Terry, a su vicepresidente Edgardo Seoane, al líder del partido UNO (Unión Nacional Odriísta), Manuel A. Odría y al parlamentario aprista Armando Villanueva, como personajes que no tienen contacto ni cercanía con el pueblo. Belaunde aparece conversando con Seoane como lo muestra su mano levantada y sus labios entreabiertos, Odría sonríe y mira el horizonte, Villanueva descansa como lo muestran sus brazos detrás de la nuca. Sus posiciones y rasgos físicos transmiten la idea de un ambiente de despreocupación y reposo. Si bien estos políticos no son representados como personajes maquiavéli$\cos$, sus actitudes los presentan como incompetentes e indiferentes a la crisis económica.

En la sección inferior de la imagen aparece, en cambio, una escena contraria, con el coronel "en tierra", representado en movimiento, como lo muestran las líneas paralelas junto a sus brazos, la camisa remangada y sus manos ajustando las ruedas de la oruga de un tanque de guerra. Si bien existen ciertos rasgos de ridiculización en la representación del coronel, a través de las cejas pequeñas y del bigote desordenado, La Olla busca transmitir un discurso a favor de las Fuerzas Armadas, puesto que contrariamente a los políticos, éstas aparecen como una institución dinámica y eficaz. La amenaza del golpe de Estado es sugerida por el caricaturista tanto por la inacción de los políticos, y la presencia de los militares, como por las ruedas y tuercas del tanque ("devaluación", "déficit", "costo de vida", "inmoralidad administrativa", "contrabando"), que aluden a una política gubernamental deficiente y que aparecen como las justificaciones de una posible toma de poder militar. La situación dramática se hace evidente a través de una amenaza latente de un cambio en el orden constitucional, que está a punto de ocurrir sin que los políticos de los diferentes partidos se den cuenta.

15 Diccionario de la Real Academia de la Lengua Española, 2001: 1404. 
Los personajes femeninos en la sección derecha de la imagen, cuyos rostros y cuerpos se presentan como modelos de belleza ideal, observan y comentan entre ellas la escena. Así como en la caricatura anterior, estos personajes pueden ser identificados como encarnaciones de la opinión pública, ya que están en la periferia de la acción y comentan lo que sucede con un cierto entendimiento de los hechos. Sus posiciones, junto al coronel y sus comentarios a través del globo con rabillo, demuestran que perciben el riesgo de un golpe militar, aunque no lo digan de manera explícita. Si Hernán Bartra representa a dos jóvenes mujeres que, a pesar de ser provocativas y de tener rostros angelicales, poseen la agudeza de entender la situación política, es para enfatizar la incapacidad intelectual de los viejos políticos, que no se percatan de la "amenaza militar".

La caída en la popularidad del Gobierno de Belaunde, que se presenta en las caricaturas políticas publicadas a partir de septiembre de 1967 , se refleja concretamente en las elecciones municipales de ese mismo año. A raíz del fallecimiento del diputado de Acción Popular, Ciro Alegría, en noviembre de 1967, se organizan elecciones complementarias; y estas elecciones rápidamente adquieren un rol plebiscitario, convirtiéndose en un momento clave para evaluar la aprobación del Gobierno de Belaunde en el electorado limeño, que representa la mitad de la población electoral peruana y que es considerado además como uno de los bastiones del partido Acción Popular ${ }^{16}$. La derrota del candidato de la Alianza AP-DC, Carlos Cueto Fernandini ante el candidato de la Coalición APRA-UNO, Enrique Chirinos Soto, cuyo lema era "tu protesta es mi protesta"17, marca entonces un nuevo período político caracterizado por la impopularidad creciente de Belaunde.

A mediados de 1968, las caricaturas políticas de los medios de prensa presentan constantemente la imagen de un presidente débil y sin liderazgo. La ridiculización reiterada de Belaunde y la evocación, por parte de La Olla, de la posibilidad de un golpe militar, demuestran la existencia de una crisis política cada vez mayor. El único medio de prensa que defiende al Gobierno es el diario Expreso, aunque ya no lo hace de manera visual como antes de setiembre de 1967. "Los tiempos de popularidad de Belaunde habían pasado", escribe el periodista Juan Gargurevich ${ }^{18}$, refiriéndose al año 1968, "y las notas [de Expreso] sonaban a falso".

Es durante este período, donde las caricaturas se caracterizan por transmitir los discursos más críticos y satíricos contra la figura presidencial, que el ejecutivo decide encontrar una solución al "problema del petróleo"19. La firma del Acta de Talara el 13 de agosto de 1968 , que establecía que los yacimientos petroleros de La Brea y Pariñas fueran transferidos a la Empresa Petrolera Fiscal (EPF), empresa del Estado Peruano, fue un intento por parte del Gobierno de relegitimarse y de recobrar popularidad. Pero un mes después de haberse firmado el Acta, el 12 de setiembre de 1968, el presidente de la EPF, Carlos Loret de Mola, denuncia la desaparición de la página once del contrato firmado con el Gerente General de la International Petroleum Company (IPC), sugiriendo así un posible fraude ${ }^{20}$. Este suceso -la pérdida de la página once del Acta de Talara- marca el último período de crisis del Gobierno de Belaunde antes del golpe de Estado.

En una nueva portada de La Olla publicada el 25 de setiembre de 1968 (Fig. 5), el caricaturista representa al presidente y a los personajes políticos relacionados con la firma del Acta de Talara: el Gerente de la IPC, Fernando Espinoza, el presidente de la EPF, Carlos Loret de

16 Chirinos Lizares y Chirinos Soto, 1977: 51.

17 Prieto Celi, 2010:163.

18 Gargurevich, 1972:153.

19 Prieto Celi, 2010: 282.

20 Prieto Celi, 2010:166. 
Mola, los Ministros Pablo Carriquiry Maurer y Manuel Ulloa Elías, el presidente del Senado, Carlos Manuel Cox y el presidente de la Cámara de Diputados Andrés Tonwsend Escurra. Todos ellos aparecen como personajes femeninos y, más precisamente, como personajes costumbristas populares, como lo sugiere la leyenda "Lío de comadres", que le da título. Este término que alude, entre otras definiciones, a "la mujer a la que le gusta curiosear o chismorrear sobre los demás" ${ }^{21}$ tiene como objetivo ridiculizar a los políticos, empleando el estereotipo del travestismo.

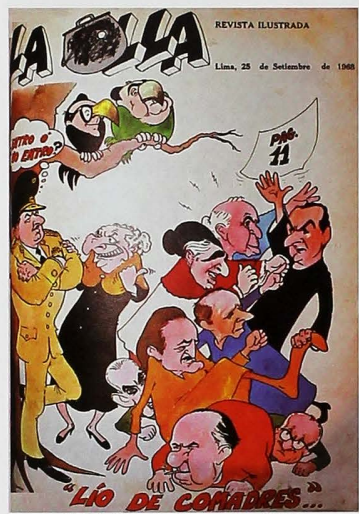

Fig.5 Anónimo, La Olla, portada del 25 de setiembre de 1968

En esta caricatura, la pelea entre los políticos peruanos no parece reflejar las fuerzas de sus oponentes, sino más bien se presenta como un combate torpe: los personajes aparecen en el suelo o inclinados, unos sobre otros mientras pelean con pequeños golpes, como lo muestran sus manos extendidas. Mientras que los miembros del Gobierno belaundista se presentan como personajes femeninos, los aspirantes candidatos a las elecciones presidenciales de 1969, Luis Bedoya Reyes (apodado por los medios de prensa como "el Tucán”) y Víctor Raúl Haya de la Torre, son representados como dos buitres, aves que simbolizan en la cultura popular, la muerte. Retomando este tópico popular, el caricaturista de La Olla representa a Bedoya Reyes y a Haya de la Torre, apoyados sobre la rama de un árbol observando la disputa de las "comadres", lo que sugiere que esperan la "muerte figurada" del Gobierno belaundista.

Su pasividad también forma parte de un discurso crítico a la oposición, ya que se les presenta como un grupo político que no interviene en medio del caos para no dañarse y que por lo tanto no se preocupa por el porvenir nacional sino por sus propias aspiraciones políticas. Mientras que lo femenino es asociado en la caricatura de La Olla al chismorreo y a la intriga, como lo muestra el gesto de Beltrán, a lo humorístico y a lo ineficaz, como lo sugieren Belaunde y sus Ministros; lo animalesco es asociado a la perfidia, como lo sugieren Bedoya Reyes y Haya de la Torre. Solo lo masculino aparece representado como un símbolo de fortaleza y rectitud, como lo pone de manifiesto el personaje de Velasco Alvarado.

El aspecto físico de este último, -robusto- y sus gestos, como los brazos cruzados y la pierna apoyada sobre el árbol, transmiten un discurso de seguridad, demostrando que su disyuntiva - "¿Entro o no entro?"- traducida a través de un globo nube con un rabillo, podría concretizarse. Si bien la posibilidad de que un golpe de Estado militar derroque al Gobierno de Belaunde había sido ya sugerida de manera verbal en el semanario La Olla, es solo a través del modo visual que se menciona explícitamente a Velasco como el líder de un potencial y probable golpe. Presentar, a través de una caricatura, a Velasco como el posible líder de un golpe militar es una manera de introducir un discurso importante en la esfera pública sin dar explicaciones y sin tener que asumir ninguna responsabilidad. En este período, la caricatura demuestra su rol clave en la transmisión de discursos que la

21 Mitkova, 2007: 95. 
prensa escrita no puede reproducir sea por razones legales, sea porque tiene que acoplarse a la imagen de un "periodismo responsable".

Si bien el pueblo no se levantó contra el Gobierno de Belaunde, las caricaturas sí pudieron contribuir a desestabilizar el régimen. Los constantes ataques a la personalidad del presidente, que representaron el "asesinato simbólico del líder", conllevaron a que se llevara a cabo, sin mayores sorpresas, un golpe de Estado en octubre de $1968^{22}$. Las críticas visuales sobre la falta de liderazgo de Belaunde hicieron que éste fuera percibido como un mandatario ausente, y por lo tanto contribuyeron a hacer válida la amenaza de un golpe militar. En su libro de 1985 Communication and Persuasion, Harry Jamieson sostiene que el carácter artificial de las metáforas puede desaparecer frente a los ojos del lector ${ }^{23}$, y considero que esto es lo que ocurrió durante este período: la asociación visual de Belaunde con la desorientación y la indecisión que aparece en medios de prensa con diferentes posiciones políticas, pudo haber tenido un impacto considerable en el imaginario colectivo. Mientras que en las caricaturas de La Tribuna, Belaunde aparece como un capitán que hunde su barco (Fig. 2); en El Comercio, La Prensa y La Olla, el mandatario es representado como un doctor que no puede curar (Fig. 1), como un jardinero que no sabe cultivar (Fig. 3), como un político infantilizado y desconectado de la realidad nacional (Fig. 4) o como una comadre que pelea débilmente (Fig. 5). Si las caricaturas son creadoras de imágenes en la esfera pública, resulta indudable que a través de estas caricaturas se creó una imagen pública de Belaunde como un mandatario incapaz de dirigir el país, dejándose simbólicamente vacante el sillón presidencial.

\section{Bibliografia}

Chirinos Lizares, Guido y Chirinos Soto, Enrique

1977 El Septenato 1968-1975. Lima: Alfa.

Diccionario de la Real Academia de la Lengua Española

2001 Vigésima Segunda Edición. Madrid: Rodesa."El pronunciamiento de la Fuerza Armada", El Comercio, 4 de octubre de 1968: 2.

Fisher, Irvin

1933 "Debt-Deflation Theory of Great Depressions". Econometrica, 4: 337-357.

Gargurevich, Juan

1972 Mito y verdad de los diarios de Lima. Lima: Gráfica Labor.

1991 Historia de la prensa peruana 1594-1990. Lima: La voz.

Gombrich, Ernst

1999 Los usos de las imágenes. Estudio sobre la función social del arte y la comunicación visual. Madrid: Phaidon.

2003 Méditations sur un cheval de bois et autres essais sur la théorie de l'art. Phaidon. Paris.

Herrera-Soler, Honesto y White, Michael

2012 Metaphor and Mills: Figurative Language in Business and Economics. Berlin: De Gruyter Mouton.
Jamieson, Harry

1985 Communication and Persuasion. Londres: Croom Helm.

Keynes, John Maynard

1930 The Applied Theory of Money. Treatise on Money. Londres: Macmillan.

Koetzle, W. y Brunell T.L.

1996 "Lip-Reading, Draft-Dodging, and Perotnoia: Presidential Campaigns in Editorial Cartoons". Press/Politics, $4: 111-113$.

Mitkova, Adriana

2007 "Estereotipos del habla femenina en el refranero español". Paremia, 16: 89-97.

Plantureux, Jean

1998 La France Dopée. Paris: Seuil.

Prieto Celi, Federico

2010 Así se hizo el Perú. Crónica Política de 1939 a 2009. Lima: Norma.

Seymour-Ure, Colin

1986 Drawn and Quartered: The Election in Cartoons. En: Political Communications: The General Election Campaign of 1983. Crewe, Ivor y Haroop, Martin (ed): 160176. Cambridge: Cambridge University Press.

22 Un día después del golpe, el diario de los Miro Quesada escribe: "Es inútil disfrazar la realidad con visiones o espejismos. El proceso que ha culminado con el derrocamiento del Presidente de la República y la clausura del Congreso no se ha incubado antier, ni una semana antes. Es el resultado penoso de un lento deterioro institucional [...]". En: El Comercio, 4 de octubre de 1968, p. 2.

23

Jamieson, 1985: 93 


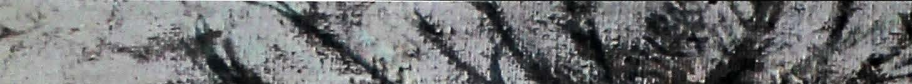

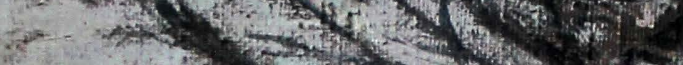

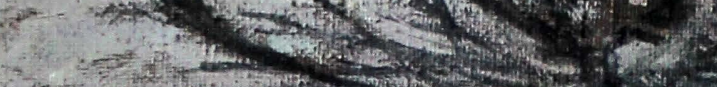

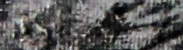

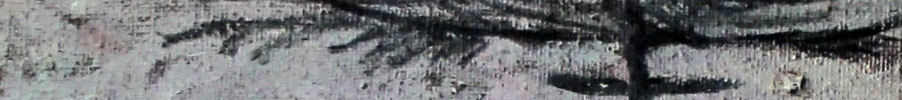

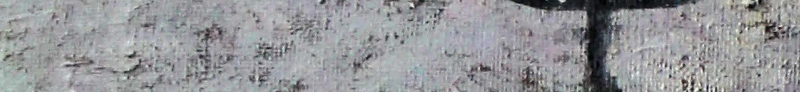

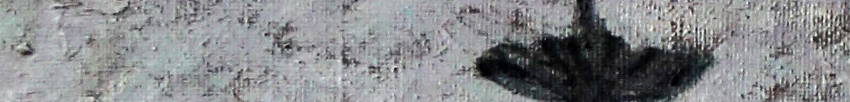

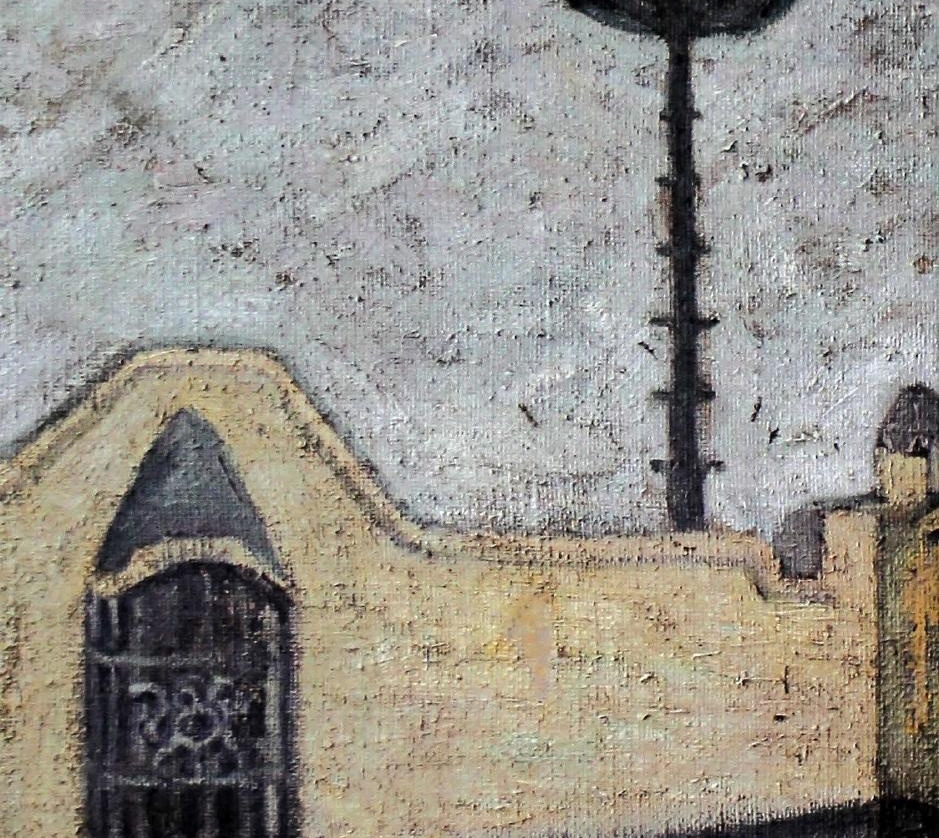

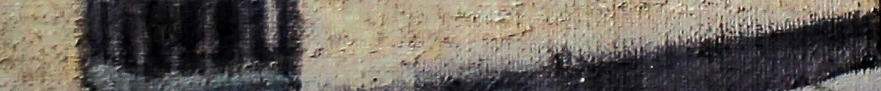

g.

Julia Codesido. detalle de Convento de los, Descaleos (19917). óleo sobsulienzo colección particular. 2. Julia Codesido. detalle de Convento de los, Descales (1917). óleo sobsulienzo colección particular.

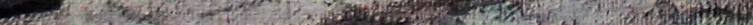

